https://doi.org/10.18485/iipe_cpti.2020.ch11

\title{
ISLAMIZAM I EVROPSKI DESNI ODGOVOR: ULJE NA VATRU
}

\begin{abstract}
Milovan SUBOTIĆ
Apstrakt: Predmet diskusije i oprečnih stavova u tumačenju islamizma vezan je za supremaciju verskog ili političkog u njegovim doktrinarnim učenjima i neposrednim ispoljavanjima. $\mathrm{O}$ tome da je islamizam par exellence politička ideologija, a ne profilisan i unifikovan islam novog vremena, ukazuje i sve izraženiji odgovor na njega koji je ekstremno desnog karaktera. Da li islamizam i njegova sve veća prisutnost u savremenim evropskim narativima izaziva povećanu posvećenost veri evropskih hrišćana ili sjajan šlagvort evropskim desničarima u vremenu u kojem se desni limes pomera sve „dešnje”? Da li su veća pretnja onome što popularno nazivamo "evropskim vrednostima”, a suštinski se odnosi na prava i slobode elaborirane $u$ "Konvenciji za zaštitu ljudskih prava i osnovnih sloboda”, moderni islamisti ili protagonisti krajnje desnog evropskog odgovora? Ovaj rad će stoga, nakon jasne elaboracije islamizma kao političkog fenomena koji je našao utočište u okrilju najmlađeg monoteizma, analizirati kapilarnost između njega i rasta ekstremne evropske desnice i pokušati da odgovori na delegirana pitanja.

Ključne reči: islamizam, krajnja desnica, konfliktnost, terorizam, populizam, demokratija.
\end{abstract}

\section{Islamizam: na ušću religije i politike}

Poznavaoci prilika diljem savremenog islamskog sveta već nekoliko decenija ističu da politički islam, ${ }^{2}$ u svojim različitim formama, nudi ozbiljan

${ }^{1}$ Autor je naučni saradnik u Institutu za strategijska istraživanja, Beograd, e-mail: milovan.subotic@mod.gov.rs

${ }^{2}$ Termini politički islam ili islamizam koriste se u literaturi za opisivanje političkoreligijskog pokreta koji smatra da je islam istovremeno religija (din), način života (dunya) i država (dawla) i da stoga društvo i država trebaju biti organizovani u skladu sa principima i odredbama islamskog prava (shar'ia). Videti više o suštini savremenog islamizma oličenog u simbiotičkom zagrljaju politike i religije u: Graham Fuller, The 
ideološki izazov ne samo režimima zemalja čije stanovništvo praktikuje načela najmlađeg monoteizma, već i postojećem svetskom poretku. Ovo osnaženo interesovanje usmereno prema povratku tradicionalnim vrednostima i načelima islama, ne očituje se samo u umnožavanju različitih islamističkih organizacija i stranaka sa nesumnjivim islamističkim predznakom koje se otvoreno zalažu za reorganizaciju društva u skladu sa pomenutim načelima, već i u trendu povratka širokih arapskih masa islamskim normama i navikama ponašanja. Da povratak islamu predaka, kako islamisti najčešće opisuju svoja stremljenja, postaje sve prisutniji bihejvioralni obrazac u muslimanskim društvima prepoznaje se u mnogim aspektima svakodnevnog života - $\mathrm{u}$ redovnom upražnjavanju molitvi $\mathrm{u}$ džamijama, striktnom poštovanju osnovnih dužnosti islama, ${ }^{3}$ nekonzumiranju alkohola i svih artikala prehrane koji nisu u skladu sa halal sertifikatom, ${ }^{4}$ te sve izraženijem odbacivanju zapadnih društvenih i seksualnih navika. Takođe, opšti trend u odevanju izražen je kroz prihvatanje distinktivne „islamske odeće” u vidu hidžaba (nikaba, burke) za žene i džalabije ${ }^{5}$ za muškarce, te puštanju brade po uzoru na proroka Muhameda. Pored toga, u poslednjih nekoliko decenija svedoci smo naglog rasta broja islamskih bogomolja, kao i eksplozije prisutnosti verskih sadržaja

Future of Political Islam, Palgrave MacMillan, New York, 2003. Takođe, o supremirajućim političkim elementima i motivima islamista videti: Olivier Roy, The Failure of Political Islam, Harvard University Press, Cambridge, Massachusetts, 1994.

${ }^{3}$ Pet je osnovnih dužnosti ili temelja (fundamenata) islama i njih čine: 1. šehadet (shahada) - svedočenje vere (nema boga osim Alaha i Muhamed je njegov poslanik). Šehadet je temelj ispravnosti ljudskih dela i njihovog prijema kod Alaha. 2. namaz/salat - redovna molitva, kao najbolje sredstvo kojim se postiže duševni mir i oslobađa od teskobe i svakodnevnog stresa 3. sawn - post tokom svetog meseca Ramazana, 4. zekat obavezni verski doprinos (porez za sirotinju) i 5. hadž - hodočašće u Meku za sve finansijski i fizički sposobne muslimane i muslimanke. Prema: Muhamed Nezir Mehanović, "Osnovne islamske dužnosti i njihov utjecaj na izgradnju morala", Preporod, Sarajevo, 4. jun 2017.

${ }^{4}$ Halal na arapskom jeziku znači dozvoljeno. Kada se kaže 'dozvoljeno' misli se na hranu koja je pripremljena po šerijatskim zakonima i većina muslimana širom sveta primenjuje ovaj način ishrane. Halal sertifikat važi jednu godinu. U toku trajanja sertifikata vrši se redovna kontrola od strane halal kontrolora i takođe se vrši uzorkovanje proizvoda sa tržišta. Na taj način se obezbeđuje sigurnost da neće biti religijskog skrnavljenja proizvoda u bilo kojoj fazi proizvodnje.

${ }^{5}$ Zalivski Arapi nose poznate bele haljine koje se u Omanu zovu dišdaše a u drugim islamskim zemljama džalabije, kandore ili tob. 
u medijima, bujanja verske literature, te izlaganje delova Kurana i ostalih islamskih slogana na javnim prostorima, trgovima i vladinim zgradama, što ukazuje na širenje svega što je vezano za islam takvom brzinom kao da je reč o nekom modnom trendu.

Ovo masovno okretanje islamu kao temelju identiteta i izvoru ideja, vrednosti i društvenih normi svakako svedoči o vitalnosti islama kao religije, ali i o sposobnosti islamista da ispune ideološko-političku prazninu koja je usledila nakon kolapsa arapskog modela socioekonomskog razvoja i povlačenja sekularnih ideologija (kako arapskog nacionalizma, tako i osobenog arapskog socijalizma) na kojima se taj model temeljio.

Prema osnovama sekularizacije, povlačenje religije iz javne sfere i opadanje njenog uticaja na društvo i pojedinca predstavlja jednu od direktnih posledica procesa modernizacije. Trijumf islamske revolucije $u$ Iranu, zemlji u kojoj su reforme sprovođene od strane režima šaha Reze Pahlavija (Mohammad Reza Pahlavi), u značajnoj (možda ne i u dovoljnoj) meri uspele su da modernizuju najznačajnije sektore iranskog društva, sa stanovišta modernističke (sekularizacijske) teorije predstavljao je tek anomaliju, ili izuzetak koji potvrđuje pravilo. ${ }^{6}$ Ako se na ovaj događaj iz 1979. godine, može gledati i kao na uspeh bunta osiromašenih i marginalizovanih gubitnika procesa modernizacije iranskog društva, onda je sled događaja koji će uslediti nakon „homeinizacije” Irana nedvosmisleno pokazao da se ovakva kauzalnost ne može uzeti za konačnu i jedinu istinu, te da je odnos između modernosti i religije daleko komplikovaniji od onog koji je pretpostavljen u tezi sekularizacije.

Nadolazeće godine i decenije otvorile su širom vrata "tihoj revoluciji” koja se nezaustavljivo širila diljem Bliskog istoka, i koja je nedvosmisleno upozorila da islamski preporod predstavlja fenomen sa kojim treba dugoročno računati, te da porast uticaja islama nije moguće objasniti na nivou puke reakcije od stane "zaostalih", tradicionalnih delova društva. Naprotiv, eksplicitne manifestacije povratka islamskom načinu života postajale su najvidlijivije upravo $u$ najurbanijim centrima $\mathrm{i}$ velikim

\footnotetext{
${ }^{6} \mathrm{O}$ (ne)uspešnim reformama Reze Pahlavija u predrevolucionarnom Iranu na primeru specifičnog odevanja u skladu sa islamskim standardima, videti: Gillian VogelsangEastwood, "Reza Shah's Dress Reforms in Iran", in: Gillian Vogelsang-Eastwood (ed.), Berg Encyclopedia of World Dress and Fashion, Central and Southwest Asia, Berg Publishers, Oxford, 2010, pp. 308-312.
} 
gradovima. Jednovremeno, ovaj povratak ,fundamentima islama" najvidljiviji je bio upravo među obrazovanim, modernizmu sklonim segmentima srednje klase koja je samo generaciju-dve ranije predstavljala glavno socijalno uporište sekularnih arapskih režima i iz koje su se već utabanim matricama regrutovali pobornici različitih varijanti ideologije arapskog nacionalizma i socijalizma. Dakle, desilo se sve ono što moderne društvene nauke tog vremena nisu predvidele. Modernizacija ne samo da nije vodila kapitulaciji religije pred silama naučno-tehnološkog razvoja, već je proizvela bar jednako modernu formu religijskog aktivizma usmerenog na osvajanje političkog polja u cilju promptne desekularizacije sociokulturnog prostora ovih društava. U tom smislu posmatran, savremeni fundamentalizam nije naprosto povratak tradiciji, već predstavlja moderni odgovor na probleme savremenog društva i bunt protiv očigledno labavo uspostavljenih kulturnih manifestacija kasne modernosti kao što su moralni relativizam, ontološka neizvesnost $\mathrm{i}$ insistiranje na fluidnosti identiteta.

Iako se načelno može reći da savremeni fundamentalistički pokreti dele niz zajedničkih karakteristika, pre svega neprijateljski odnos prema vrednostima sekularnog humanizma, ${ }^{7}$ ne treba zanemarivati razlike koje proizilaze iz ideoloških i vremenom stečenih osobina proisteklih iz njihovih verskih tradicija, kao i neposrednog sociopolitičkog okruženja u kojem deluju. Na taj način posmatrani, oni se $u$ dobroj meri razlikuju ne samo $u$ sferi doktrine, već i u nizu ostalih posebnosti, poput brojnosti onih kojima

\footnotetext{
${ }^{7}$ Sekularni humanizam je humanistička filozofija koja promoviše razum, etiku i pravdu s posebnim naglaskom na odbacivanje natprirodnog i duhovnog kao izvora morala i odlučivanja. Kao termin pojavio se u XX veku kao odgovor na odavno etablirani religijski humanizam. Neki sekularni humanisti pak odbacuju taj naziv jer na njega gledaju kao na pleonazam i umesto toga koriste izraz Humanizam sa velikim „„ $\mathrm{H}^{\prime \prime}$. Kao što i sam naziv sugeriše, sekularni humanisti se zalažu za sekularizam, odnosno potpuno odbacivanje religije iz javnog života, ali i pojedinačni moralni kodeks zasnovan na sekularnim, odnosno racionalnim principima. Smatra se da svoje ideološke korene vuče iz predsokratovske grčke filozofije, konfučijanizma i prosvetiteljstva. Sekularni humanizam sa svojim blizanačkim doktrinama, evolucijom i ateizmom, neprijatelj je broj jedan savremenih fundamentalističkih pokreta. Protivnici ovog pravca često ističu da je kulturna hegemonija sekularnog humanizma rezultirala pobunom čovečanstva protiv Boga i posledičnom moralnom korupcijom društva, što se očituje u slomu institucije braka i rastakanju porodičnih vrednosti, promiskuitetnom ponašanju, širenju pornografije, homoseksualnosti i feminizma. John R. Shook, "Paul Kurtz, Atheology, and Secular Humanism", Essays in the Philosophy of Humanism, Vol. 21, No. 2, 2013, pp. 111-116.
} 
se obraćaju, odnosu prema državi i institucijama političkog sistema, te izboru strategije i metoda delovanja. ${ }^{8}$ Stoga se može zaključiti da zahvaljujući različitim kontekstima i nejednakom sociopolitičkom dometu savremeni fundamentalizmi, koji bez sumnje hrane jedan drugog, svakako ne predstavljaju identične fenomene, a naročito ne fenomene sa potencijalom proizvođenja identičnih posledica.

Globalni trend povratka religije na pozornicu bitnosti današnjeg sveta posledica je spremnosti članova savremenih fundamentalističkih pokreta da uđu u polje politike i aktivno se suprotstave onim svetovnim rešenjima za koja drže da su moralno i verski neprihvatljiva. Pa ipak, samo je na prostoru Bliskog istoka povezivanje religijskih i sociopolitičkih ciljeva poprimilo takve razmere da se može govoriti o značajnoj politizaciji religije kao distinktivnom bliskoistočnom fenomenu. Posvećeni istraživači, poput Samija Zubaide (Sami Zubaida), zapazili su da se u nekoliko poslednjih decenija „islam uspeo nametnuti kao prevlađujući idiom političkog govora kojim različite društvene grupe izražavaju svoj identitet, očekivanja i frustracije, i koriste ga u svrhu kritike ili legitimacije postojećeg društvenog poretka". ${ }^{9}$

U najkraćem, spoj političnosti i okvira koji pružaju načela najmlađeg monoteizma se $\mathrm{u}$ savremenom diskursu islamskog sveta ovaploćuje kroz dva transmisiona i ujedno interesna kanala. Kao prvo, putem forme partikularnih ideja i artikulacije sentimenata, islamizam se legitimiše kao neko ko postavlja jasne granice između "nas" i „njih" na temeljima nepremostivih razlika koje su religijskog i kulturnog karaktera. Na taj način on se javlja ne samo kao temeljac identiteta već i kao izvorište paušalnosti prilikom odnosa prema drugim religijama i kulturama. Sa druge strane, formu političke artikulacije islama čini tzv. službeni islam, koji je prvenstveno okrenut upotrebi ovog monoteizma u svrhu legitimacije režima i vladajućih elita (dinastija).$^{10}$ Islamizam na ovom primeru pokazuje

${ }^{8} \mathrm{O}$ razlikama između savremenih fundamentalizama više u: Malise Ruthven, Fundamentalism: The Search for Meaning, Oxford University Press, Oxford, 2004, pp. 9-16.

${ }^{9}$ Sami Zubaida, Islam, the People and the State: Political Ideas and Movements in the Middle East, I. B. Taurus \& Co., London and New York, 2009, p. 149.

${ }^{10}$ Još od sredine $X X$ veka monarhijski vladari u svojoj naslednoj vertikali kontinuirano igraju na kartu islama, ne samo u borbi protiv domaćih opozicionih snaga već i u neutralizaciji kritika od strane radikalnih arapskih režima. Najbolji primer za to jeste saudijski establišment, čija je karakteristika spoljne politike u odnosu na arapske 
naročito izraženu elastičnost. Bilo da je reč o režimima sa jasno izraženim islamskim identitetom (Saudijska Arabija, Maroko, Iran), ili pak o režimima oličenim kroz sekularne autokratije (Sirija i donedavno Irak i Egipat), bez sumnje se može konstatovati da su u svima vladajuće elite koristile islam, i još uvek ga koriste, za postizanje političkog konsenzusa i šire mobilizacije stanovništva u cilju generisanja masovne podrške. Takođe, islamizam predstavlja i sofisticirani alat za opravdanje unutrašnje i spoljne politike, ali i za diskreditaciju opozicije kojoj se u takvim situacijama spočitava delovanje na antiislamskim osnovama. ${ }^{11}$

Ulazak islama u političko polje delovanja u značajnoj je meri posledica aktivne uključenosti arapskih režima u nadmetanje oko interpretacije islamskih simbola i kontrole nad formalnim i neformalnim institucijama islama, a sve u cilju etabliranja okvira koji će podržavati interese i moć vladajućih struktura. Tako dolazimo i do operacionalno najvažnije forme političke artikulacije islama, a to su savremene islamističke organizacije i političke stranke koje protežiraju ovaj narativ. One imaju jasno postavljen politički cilj - osvajanje vlasti u cilju uspostave poretka koji će se temeljiti na islamskom pravu i principima socijalne pravde. Islamizam sa svojim nesumnjivim revivalističkim kapacitetom stoga predstavlja urbani fenomen koji odlikuje nastupanje politički osvešćene i moderne političke snage sa čvrstom organizacijskom strukturom i razrađenim sistemom regrutacije članstva. Reč je o osvajanju (preuzimanju) vlasti u društvima u kojima deluju i o oblikovanju društva prema njihovom ideološkom modelu, onom koji tumači i koristi islam kao religiju. Potvrdu za to nalazimo u činjenici da se „islamizam javlja kao alternativa vladajućim porecima čak i u društvima koja svoj legitimitet baštine na islamu poput Saudijske Arabije, Jordana ili Maroka". ${ }^{12}$ Uprkos razlikama koje postoje među islamističkim organizacijama, njih povezuje uverenje da islam nije tek jedan od mogućih

zemlje oličena i u finansiranju islamističkih organizacija u drugim zemljama kao protivtežu arapskom nacionalizmu i radikalizmu. Dogogodišnji libijski vođa Muamer Gadafi (Muammar al-Gaddafi), inače sekularni autokrata, u jednom trenutku je posegao za islamom i postao svojevrsni partner Saudijske Arabije u ovom izvoznom potencijalu islamskog narativa.

${ }^{11}$ Prema: Salim Cevik, "Myths and Realities on Islam and Democracy in the Middle East", Estudios Políticos, No. 38, 2011, pp. 121-144.

12 Tarik Kulenović, Politički islam: osnovni pojmovi, autori i skupine jednog modernog političkog pokreta, VBZ, Zagreb, 2008, str. 5. 
društvenih poredaka, već jedini pravi put koji treba slediti da bi se ostvarilo blagostanje i društveni razvoj, te povratila moć i dostojanstvo diljem muslimanskog sveta. Pa ipak, uvažavajući činjenicu da socioistorijsko iskustvo muslimana nije monolitno, isto se može reći i za programe i aktivnosti različitih islamističkih organizacija.

Tako su sunitski i šiitski islamizam sve samo ne identični. Oni pokazuju značajne razlike u strukturi vođstva i percipiranju političkog autoriteta. ${ }^{13}$ Nadalje, značajne kvalitativne razlike u programima i tretmanu društva postoje i među sunitskim islamistima. Dok su radikalne islamističke grupe u Egiptu, Alžiru ili u Iraku, izabrale ambiciozne ofanzivne strategije i mehanizme osvajanja vlasti, druge mahom preferiraju model saradnje i postepene promene, kao što je recimo slučaj u Jordanu, delom Jemenu ili Kuvajtu. Iako sve te grupe, bez sumnje, povezuje snažna identifikacija sa islamskom tradicijom, njihove interpretacije te tradicije se $u$ mnogim detaljima značajno razlikuju. ${ }^{14}$ Iako se po pravilu sve zalažu za implementaciju šerijatskog zakona i uspostavljanje „pravednog islamskog poretka" (nizam islami), pod time neretko podrazumevaju dijametralno različite koncepcije političkog i socioekonomskog sistema. Zato naglašavanje određenih aspekata islamske istorije i predanja $u$ odnosu na druge govori u prilog tezi da politizacija islama u savremenom kontekstu ne predstavlja puko oživljavanje islamske tradicije, već naglašeno selektivnu i ideološki motivisanu reformulaciju te tradicije u svrhu suočavanja sa izazovima modernog vremena.

${ }^{13}$ Čitava duhovna građevina šiita zasnivala se, i zasniva, na pojmu valaja (walaya) ljubav i obožavanje Alija, koji je postao prvi šiitski imam. Drugim rečima, valaja prema Aliju (p)ostaje jedini kriterijum za procenjivanje istinske vere. Imama šiiti vide kao deo božijeg bića, pa otuda ta svetost koja mu se podrazumeva i poštuje. Tako je imam bezmalo u rangu katoličkog pape - nepovrediv. Prema: Olga Zirojević, „Šiiti i suniti", Republika, 592-599, 30. jun 2015.

${ }^{14}$ Islamolog Tilman Zajedenštiker nudi u koncizno napisanoj monografiji: Tilman Seidensticker: "Islamismus. Geschichte, Vordenker, Organisationen", C.H. Beck Verlag, Munchen, 2014, kompaktan pregled razlika između vahabista i njihovih različitih varijeteta (tradicionalista, akcionista i džihadista), Muslimanske braće i nekih drugih islamističkih organizacija i pokreta današnjice i objašnjava njihove lajtmotive i ciljeve. 


\section{Greške u kolokvijalnom percipiranju islamizma u zapadnoj kulturi}

Tradicionalni orijentalizam i njegovo shvatanje islamskog društva i kulture protežiraju stanovište prema kojem se ove vrednosti suštinski razlikuju od društava i kulture Zapada, oličenih u onome što već odomaćeno nazivamo „evropskim vrednostima”. Neuspeh sekularne politike i odbacivanje modernih evropskih institucionalnih rešenja, kao što su pluralizam, demokratija i slobodno tržište, od strane značajnog dela islamističkih pokreta, postaju manifestacije posebne suštine islama kao sociokulturne formacije koja je neprijemčiva za modernizaciju. Ovakvo shvatanje, prema kojem se aktuelne manifestacije islamske politike $\mathrm{u}$ zemljama Bliskog istoka u celosti mogu objasniti kao proizvod unutrašnjeg kulturnog razvoja i osobina njihovih specifičnih kulturno-verskih tradicija, ima brojne zagovornike i u zapadnim diplomatskim krugovima, pa i delovima akademske zajednice. I zaista je činjenica da prilikom objašnjenja složenog društvenog fenomena, kao što je islamski preporod, treba ozbiljno računati na postojanje kulturno-verske tradicije.

Međutim, koliko god važna, kultura sama po sebi ne može dati odgovor na pitanje zašto se jedna politička zajednica opredeljuje za ovako specifičan program društveno-političkog razvoja, te na koji način i zašto dolazi do promena u ideološkoj sferi društva. Objašnjenje koje bi se tražilo isključivo u sferi i terminologiji kulture ima smisla samo ukoliko predstavlja element šire objašnjujućeg okvira, onog $u$ kojem se uloga ideja $u$ oblikovanju sociopolitičke stvarnosti posmatra kroz prizmu njihove uslovljenosti strukturalnim kategorijama poput države, klase i političkog sistema, te sve komplikovanijim procesima na međunarodnoj i regionalnoj sceni. Pretpostavka inertnosti, odnosno percepcija prema kojoj kulturni i socijalni kontinuitet ne zahtevaju dalje nijansiranje i objašnjenje gubi iz vida činjenicu da se sa svakom novom generacijom taj kontinuitet mora iznova uspostaviti, što neretko može da iziskuje značajne napore. Teorija bezuslovne kulturne inercije „previđa ulogu indoktrinacije i obrazovanja u održanju konkretnih interesa i privilegija i time zanemaruje komplikovani proces prenošenja kulture s jedne generacije na drugu" ${ }^{\prime 15}$ Drugim rečima, priznavanje uloge ideja u kreiranju institucionalnog poretka društva ne vodi nužno

${ }^{15}$ Hans Theodorus Blokland, Freedom and culture in western society, Routledge, London, 1997, p. 287. 
prihvatanju kulturnih i religijskih konvencija, kao istorijski kodiranih konstanti koje u celosti determinišu tok i intenzitet društvenog razvoja.

Zato je savremeni islamizam potrebno posmatrati $\mathrm{u}$ njegovom socioistorijskom kontekstu, i to dvojako: kao element društvenih promena i kao odgovor na strukturalnu krizu bliskoistočnih društava koja je kulminirala u poslednjih tridesetak godina $X X$ veka. On uključuje raznolike kolektivne aktere koji deluju u ime islama: grupe za molitvu i učenje, kulturna društva i humanitarne organizacije, grupe za tumačenje islamskih spisa, politička udruženja i stranke, pa i različite militantne grupe islamističkog tipa i terorističke organizacije. Navedeni akteri se međusobno razlikuju po mnogo čemu: da li svoje delovanje vide u području civilnog društva ili sferi politike, da li poseduju čvrstu formalnu organizaciju, ili su tek labavo povezane neformalne grupe, da li koriste legalna sredstva političke borbe ili pribegavaju nasilju i slično. ${ }^{16}$ Ono što ih pak povezuje jeste delovanje usmereno ka transformaciji društva i njegovih institucija. Uvažavajući ovako razložene partikule šireg problema najmanje ćemo pogrešiti ukoliko dinamiku, proces i organizaciju islamskog aktivizma posmatramo kroz termine kolektivne akcije, kao elemente protestnih pokreta koji nisu svojstveni samo sociokulturnoj formaciji islama. Kvintan Viktorovič (Quintan Wictorowicz) stoga i ističe kako savremeni aktivizam islamističkog tipa nije sui generis, već da „uprkos postojanju ideoloških i svetonazorskih razlika, kolektivna akcija sama po sebi, kao i njeni mehanizmi, demonstriraju konzistentnost islamizma sa drugim modernim društvenim pokretima". ${ }^{17}$

Islamistički pokret očito deluje u specifičnom socijalnom kontekstu, koristeći različite organizacione resurse u svrhu mobilizacije i transformacije individualnog nezadovoljstva u širi, kolektivni protest. Na taktičkom i

${ }^{16}$ Više na temu raznolikosti aktera savremenog islamizma u: Shadi Hamid and Rashid Dar, "Islamism, Salafism, and jihadism: A primer", Markaz, July 15, 2016, https:/ / www.brookings.edu/blog/markaz/2016/07/15/islamism-salafism-andjihadism-a-primer/ 29/05/2020.

${ }^{17}$ Quintan Wiktorowicz, "Introduction: Islamic Activism and Social Movement Theory", in: Quintan Wiktorowicz (ed.), Islamic Activism: A Social Movement Theory Approach, Indiana University Press, Bloomington, 2004. pp. 3-4. Takođe, u kontekstu sagledavanja islamizma iz ugla višestruke međuzavisnosti sa ostalim sociopolitičkim ekvivalentima u savremenom svetu, pogledati i: Quintan Wiktorowicz and Karl Kaltenthaler, "The rationality of radical Islam", Political Science Quarterly, Vol. 121, No. 2, 2006, p. 421. 
strategijskom planu se takođe ponaša kao savremeni akter, prilagođavajući svoje ciljeve sa specifičnim konfiguracijama savremenog političkog prostora. $\mathrm{U}$ tom smislu, on nije skup nepovezanih manifestacija tradicionalne islamske religioznosti, već smisleni i kanalisani protest protiv prevladavajućih obrazaca društvenog i političkog života u dotadašnjim islamskim društvima, što se svakako reflektuje i na relaciju novih islamista prema Zapadu. Osim neporecive bitnosti problema, koje su islamisti utisnuli u svakodnevnicu savremenog sveta, ono što dodatno komplikuje problem jeste i nerazumevanje ovog fenomena od strane Zapada, koji se već duže vreme takođe ne može posmatrati kao monolit. Razumevanje savremenog islamskog preporoda otežava ne samo nedostatak pouzdanih informacija o karakteru islamističkih grupa i organizacija već i odsutnost akademskog opreza kod značajnog dela zapadnih autora. Osim na stranicama štampanih i internet medija, i na policama knjižara neretko se mogu naći knjige u kojima se upozorava zapadna javnost na opasnosti koje islam predstavlja po zapadne vrednosti i način života. Ono na šta je još u prvim godinama nakon Iranske revolucije ukazivao poznati egipatski sociolog Desouki (Ali El Deen Hilal Dessouki), a odnosi se na pogrešnu percepciju Zapada prema fenomenu koji je tek uzimao maha, u dobroj meri se koristi i dan-danas. On je kao ključne tendencije u nerazumevanju tzv. novog islama koje će godinama kasnije doprineti i pogrešnom odgovoru na njega, te pospešiti produbljivanje problema, označio: poricanje da je reč o potpuno novom fenomenu; senzacionalizam kao medijsku, a neretko i akademsku, potporu crno-beloj matrici shvatanja problema; insistiranje na retrogradnosti oličenoj $u$ anahronizmu prema svetu racionalnosti i naučnog progresa. ${ }^{18}$

Bazna greška jeste ona koja se pravi kada se na islamizam gleda isključivo kao na nastavak ranijih formi islamskog aktivizma. Budući da savremeni islamizam ponavlja neke teme ranijih revivalističkih pokreta, kao što je insistiranje na striktnoj primeni odredaba islamskog prava, tvrdi se da on ne predstavlja distinktivan fenomen $\mathrm{u}$ istorijskom kontekstu koji bi zahtevao posve novo i nezavisno istraživanje. Međutim, kao što je već

${ }^{18}$ Navedene tendencije taksativnog tipa su navedene prema: Ali E. Hillal Dessouki, Islamic Resurgence in the Arab World, Praeger Publishers, New York, 1982, pp. 5-6. Takođe, na temu aktuelnog trenutka arapskih država i njihovih grešaka $u$ spoljnopolitičkom kontekstu koji se mahom tiču odnosa sa EU i SAD, više u: Bahgat Korany and Hilal Dessouki, The Foreign Policies of Arab States: The Challenge of Change, Taylor \& Francis Ltd, Milton Park, 2019. 
rečeno, on se i ideološki i organizaciono značajno razlikuje od svojih prethodnika. Lociran je u urbanim naseljima, a protagonisti su neretko najobrazovaniji ljudi školovani na zapadnim univerzitetima, što utiče na razlike u strategijama mobilizacije socijalne podrške i političkog delovanja i čini ga elementom modernog političkog polja. On uključuje aktivističke grupe koje na islam gledaju i kao na religiju, i kao na političku ideologiju, i koje stoga predstavljaju nedvosmislen otklon od islamske tradicije. Ono što takođe oponira stavu da je islamizam puko nasleđe i ponavljanje dosadašnje istorije islamskih društava jeste i činjenica da islamističke organizacije i stranke, sa izuzetkom Irana, ne vode tradicionalne verske vođe već laička inteligencija sa diplomama mahom prirodnih i tehničkih nauka. Jezgro socijalne baze islamističke podrške u zemljama Bliskog istoka nije locirano u ruralno-tradicionalističkim i siromašnijim sredinama, već u velikim urbanim centrima i među širokim slojevima domicilne srednje i niže srednje klase koja je, svakako, dobrano usvojila vrednosti konzumerizma i koja teži socioekonomskoj promociji.

Sledeća greška je najvidljivija i lako uočljiva u medijskoj eksplanaciji fenomena. To je senzacionalizam koji je postao neraskidivo vezan za sve što se odnosi na percepciju islama, i na jedan crno-beli matrični način omogućava nepotpuno i iskrivljeno shvatanje fenomena islamskog preporoda koje se iscrpljuje u slikama pokrivenih žena i bradatih muškaraca, žrtava terorističkog nasilja i egzekucija (političkih neistomišljenika, zarobljenika ili nevernih supruga) pod okriljem šerijatskih sudova. Takođe, islamistički pokret se često opisuje kao retrogradni fenomen, kao anahronizam svetu koji se temelji na vrednostima racionalnog percipiranja sveta i naučnosti. Činjenica je da islamisti neretko izražavaju paranoičan, ili možda bolje reći šizofren, stav prema modernosti. Oni prihvataju dostignuća moderne nauke i tehnologije ali istovremeno odbacuju kulturnu podršku modernosti. Međutim, ne treba zaboraviti da je u svesti islamista sekularizacija neraskidivo povezana s kolonijalnom dominacijom. ${ }^{19}$ Pored

${ }^{19}$ Upravljanje religioznom svešću je samo delimično moguće, odnosno ono ima svoje granice. Gotovo sve evropske države nastoje da destruktivne elemente religiozne svesti neutralizuju. Muslimanska religiozna kultura je raznovrsna i etablirana kroz različita kolektivna iskustva. Muslimani u Berlinu, čiji su roditelji ili preci došli iz Turske, nemaju traumatizujuće sećanje na represivnu kolonijalnu prošlost koje imaju francuski muslimani koji su preživeli rat u Alžiru. Prema: Zoran Andrić: „Ima li Evropa odgovor na islamizam?", Danas, 3. jun 2016. 
nje, takođe i sa represijom tzv. progresivnih arapskih režima koji su islam percipirali kao pretnju i kočnicu društvenog razvoja. Stoga odbacivanje zapadnih sekularnih političkih i razvojnih modela ne predstavlja nužno i isključivo beg od modernosti, već i potragu za novim i delotvornim formulama društvenog razvoja za koje se veruje da, upravo zato što su izraz autentične islamske kulture, mogu proizvesti pozitivne rezultate..$^{20}$

Ono što, takođe, treba uzeti u obzir prilikom razumevanja kompleksnog odnosa između probuđenog islama i Zapada jeste i fenomen globalizacije, koji je od koncepta budućeg sveta lišenog trvenja i konflikata došao u fazu ogoljenog nametanja određenih obrazaca sociokulturnih i ekonomskih ideja onima koji te obrasce iz više razloga ne žele da primene. ${ }^{21}$ Uostalom, sve češća razmimoilaženja zemalja zapadnog sveta prema ovom fenomenu i sve izraženiji povratak suverenističkih struja u tim zemljama svedoči da je globalistički narativ i ceo geopolitički galimatias koji je prouzrokovao, neizostavan činilac analiza o različitim konfliktnostima današnjice, pa i o predmetnom.

\section{Pretnja od islamizacije kao argument za jačanje desnog populističkog odgovora}

Unifikacija islama podrazumeva nekoliko osnovnih premisa: nepostojanje razlika između frakcionih podela (pre svega između sunita i šiita), te između različitih versko-pravnih tradicija, nepoznavanje različitih izvora islama, percipiranje islamske svete knjige kao spisa koji prvenstveno

${ }^{20}$ Prema Rašidu Ganoučiju (Rachid al-Ghannouchi), jednom od lidera tuniskog islamističkog pokreta al-Nahda (Buđenje, Preporod), problem ne leži u modernosti kao takvoj, već u „pseudomodernosti” $i$,pseudosekularizaciji” radikalnih arapskih režima koji su državu pretvorili u instrument totalne represije. Ova lažna modernost ne očituje se $u$ odvajanju religije od države već $u$ potčinjavanju religije i njenih institucija i simbola, kontroli države. Tuniski islamisti, kako ističe Al-Ghannouchi, teže „izvornoj modernosti koja uključuje ljudsku emancipaciju i pravo na slobodu izbora, promovisanje nauke i tehnološkog razvoja, izgradnju demokratskog društva uz poštovanje suverenosti naroda." Prema: Rashid Al-Ghannouchi, "Secularism in the Arab Maghreb", in: John Esposito, and Azzam Tamimi, (eds.), Islam and Secularism in the Middle East, Hurst \& Company, London, 2002, pp. 106-107.

${ }^{21}$ Više u: Hillal Dessouki and Bahgat Korany, Globalization and Arab Foreign Policies: Constraints or Marginalization?, The American University in Cairo Press, Cairo-New York 2010. 
služi za opravdanje borbe protiv nevernika, imanentan ratnički ethos, okoštalost patrijarhalnosti i tradicionalizma u kulturi muslimana. ${ }^{22} \mathrm{U}$ narednom koraku, islam se vezuje za pojmove poput fundamentalizma, ekstremizma i terorizma. Dakle, da bi se islam predstavio kao neprijateljski Drugi, najpre je neophodno izbrisati sve diferencijacije da bi sledeći korak bilo dedukcionističko poistovećivanje islama sa pojedinim teroristički ustrojenim pokretima. Unifikacija je neophodan uslov shvatanja islama kao religije naklonjene ekstremizmu. ${ }^{23}$ Ko istrajava na etabliranju ovakvog narativa u Evropi danas? Odgovor je uglavnom jednostavan - desni populisti koji se često ogrću tzv. novohrišćanstvom.

Srednjoročni trendovi u savremenoj Evropi, koji se ogledaju u slabljenju partijske demokratije, medijatizaciji politike i komercijalizaciji medija, kao i očigledno sve veći jaz između građana i "mesta na kojima se donose odluke”, mogu pomoći u objašnjavanju uspeha populizma u nekoliko poslednjih decenija. Oni pomažu i da se objasni sklonost političkih aktera da se direktno obraćaju "narodu” i usvajaju bar neke elemente populističkog stila komunikacije. ${ }^{24}$ Uvažavajući ove okolnosti lakše je razumeti zašto na talasima kriza, antiislamski (šire) i antiimigracioni populisti (uže), kao i različite evroskeptične partije postaju strukturna odlika političkog pejzaža u većini evropskih zemalja. Kriza nije neutralna kategorija u analizi društva, „, to je kategorija društvene i političke prakse koja se mobiliše da bi se obavio određeni politički posao" ${ }^{25}$ Bendžamin Mofit (Benjamin Moffitt) još određenije poentira: „Kriza ne prethodi i nije nezavisna od populističke politike, naprotiv ona je centralni deo populističke politike ${ }^{\text {“ }}{ }^{26}$ Osim Španije i Grčke, gde je

${ }^{22}$ Nataša Jovanović, Vladimir Ajzenhamer, „Unifikacija islama kao instrument hantingtonizacije migrantske krize", u: Dubravka Valić Nedeljković, Dinko Gruhonjić (ur.), Populizam, izbeglička kriza, religija, mediji, medijska istraživanja, Filozofski fakultet, Novi Sad, 2017, str. 262-263.

${ }^{23}$ Ibid., str. 263.

${ }^{24} \mathrm{U}$ delu koji se odnosi na populistički aspekt antimigratornog narativa autor će se koristiti radom: Milovan Subotić, Ivan Dimitrijević, „,Populizam kao generator desnog ekstremizma na primeru migrantske krize", Kultura polisa, br. 38, 2019, str. 295-310.

${ }^{25}$ Roger Brubaker, "Economic crisis, nationalism, and politicized ethnicity", in: Craig Calhoun and Georgi Derluguian, (eds.), The Deepening Crisis: Governance Challenges after Neoliberalism, Social Science Research Council and NYU Press, New York, 2011. p. 102.

${ }^{26}$ Benjamin Moffitt, The Global Rise of Populism: Performance, Political Style, and Representation, Stanford University Press, Redwood City, 2016, p. 111. 
populistički obrazac "otišao ulevo" i jasan je produkt ekonomske krize, populističku reakciju desnog predznaka je najdirektnije i najočevidnije izazvala migrantska kriza, koja je „više nego bilo koji drugi geopolitički proces uzdrmala evropski kontinent" ${ }^{27}$ Mada je broj imigranata 2015. godine bio veliki, on objektivno nije bio nesavladiv i nemoguć za kanalisanje. Brojka od 1,3 miliona podnetih zahteva za azil u zemljama EU gotovo je dvostruko veća od prethodno zabeleženog najvećeg broja zahteva iz 1992, ali to je i dalje samo ,jedna četvrtina jednog procenta stanovništva EU”. ${ }^{28}$ Najdirektniji politički efekti migrantske krize osetili su se u Nemačkoj, Švedskoj i Mađarskoj. U Nemačkoj, kriza je istovremeno proizvela trenutak nesvakidašnje otvorenosti (odluka Angele Merkel u septembru 2015. godine, da otvori granice Nemačke svim azilantima koji su putovali preko Mađarske i Austrije i primerena reakcija nemačkog civilnog društva), ali i snažnu reakciju protiv takve otvorenosti koja se „,manifestovala transformacijom, Alternative za Nemačku (Alternative für Deutschland, AfD) iz neoliberalne, tzv. profesorske partije $\mathrm{u}$ antiimigrantsku, antimuslimansku populističku partiju koja je ostvarila, do tada nezamislive, izborne uspehe na lokalnim izborima 2016. i saveznim izborima 2017." 29 Takođe, u Brandenburgu su na pokrajinskim izborima 2019. pobedile Socijaldemokrate, a u Saksoniji Demohrišćani. Ali, te dve stranke su $\mathrm{u}$ ovim istočnim pokrajinama ostvarile najgore rezultate od ujedinjenja Nemačke. Desničarska Alternativa za Nemačku (AfD) je u obe pokrajine drugoplasirana sa rekordnim rezultatima. ${ }^{30}$

Švedska je tokom 2015. primila više izbeglica po glavi stanovnika nego Nemačka. ${ }^{31} \mathrm{Na}$ izborima 2018. godine, ekstremno desničarska

${ }^{27}$ Ljubiša Despotović, Globalizacija i geopolitika identiteta, Kairos, Sremski Karlovci, 2017. str. 169.

${ }^{28}$ Prema: "Number of Refugees to Europe Surges to Record 1.3 Million in 2015", Pew Research Center - Global Attitudes \& Trends, August 1, 2016. http:/ / www.pew global.org/2016/08/02/number-ofrefugees-to-europe-surges-to-record-1-3-millionin-2015/pgm_2016-08-02_europe-asylum11/01/2019.

${ }^{29}$ Achim Goerres, Dennis Spies, Staffan Kumlin, The Electoral Supporter Base of the Alternative for Germany, Social Science Research Network, Rochester, NY, 2017, p. 29.

${ }^{30}$ Saša Bojić, "Nemačka štampa: Pobednici izbora kao pokisle pudle”, Deutsche Welle na srpskom jeziku, 2. septembar 2019, https:/ / www.dw.com/sr/pobednici-izborakao-pokisle-pudle/a-50257334 25/5/2020

${ }^{31}$ Prema: Jens Rydgren and Sara Van der Meiden, "Sweden, Now a Country Like All the Others? The Radical Right and the End of Swedish Exceptionalism", Working Paper, Department of Sociology, Stockholm University, 2016. 
antiimigrantska partija „,̌̌vedskih demokrata” osvojila je 17,6 posto glasova, što je značajan rast $\mathrm{u}$ odnosu na 12,9 koliko su dobili na prethodnim izborima. $^{32} \mathrm{U}$ Mađarskoj, jednoj od tada glavnih stanica na zapadnobalkanskoj ruti, premijer Viktor Orban je preuzeo antiimigrantsku inicijativu izgradnjom ograda od bodljikave žice. U populističkim krugovima desnog predznaka, on se prikazuje kao usamljeni lider koji je prihvatio zadatak da "sačuva Evropu od nje same”, a posebno od onoga što opisuje kao evropski „samoubilački liberalizam”. ${ }^{33}$ Sledeći Orbanov primer, vodeći političari u Poljskoj, Slovačkoj i Češkoj prihvatili su ovu retoriku. Koliki je besmisao u današnjoj "deideologizaciji ideologije” ilustruje i primer premijera Slovačke koji je, kao nominalno socijaldemokrata (!!), obećao da "zemlja neće primiti nijednog muslimana" ${ }^{34}$ U Austriji, još jednoj važnoj migrantskoj stanici na putu do Nemačke i severnih zemalja, podrška za radikalno desničarsku, antiimigrantsku „Partiju slobode” naglo je porasla i ona se poslednjih godina redovno nalazi na vrhu popularnosti austrijskih stranaka. To važi i za istoimenu partiju Gerta Vildersa (Geert Wilders) u Holandiji, koja "žestinom antimuslimanske retorike odskače čak i na populističkoj desnici" ${ }^{35}$ Izbeglička kriza je, kako to s pravom primećuje Klaus Ofe (Claus Offe) „kao i ekonomska pre nje, izazvala širu krizu evropskih institucija" ${ }^{36}$ Dablinski sistem koji reguliše prijavljivanje za azil počeo je da biva preopterećen, a Šengenski sporazum o slobodnom kretanju unutar EU se našao na ivici kolapsa. Sloboda kretanja, koja je bila jedna od najpopularnijih vrednosti evropske integracije, došla je u situaciju da zavisi od, očigledno poroznih, spoljnih granica Unije. Uporedo sa ovim

${ }^{22}$ Vidi: „,Švedsko upozorenje Evropi”, Radio Slobodna Evropa, 11. septembar 2018. https://www.slobodnaevropa.org/a/\%C5\%A1vedska-izbori-rezultati-desnicaporuke-evropa-populizam- / 29481858.html 14/01/2019.

${ }^{33}$ Benjamin Novak, "Orbán: Hungary's sovereignty depends on receiving EU funds", The Budapest Beacon, September 18, 2015, https://budapestbeacon.com/orban hungarys-sovereignty-depends-on-receiving-eu-funds/, 11/11/2018.

${ }^{34}$ Hardeep Matharu, "Slovakian Prime Minister says 'Islam has no place in this country' - weeks before it takes over EU presidency", Independent, May 27, 2016, https://www.independent.co.uk/news/world/europe/islam-has-no-place-in-thiscountrysays-slovakian-prime-minister-weeks-before-it-takes-over-eu-a7052506.html, $12 / 01 / 2019$.

${ }^{35}$ Koen Vossen, The Power of Populism: Geert Wilders and the Party for Freedom in the Netherlands, Taylor \& Francis, Milton Park, 2016. p. 26.

${ }^{36}$ Claus Offe, Europe entrapped, Cambridge; Malden, MA: Polity, 2016, p. 19. 
dešavanjima, pojačale su se tvrdnje koje govore o potrebi da se od migranata zaštite radna mesta, kulturni identitet i način života naroda, koji se neretko predstavlja kao „domicilni”, „starosedelački” ili „autohtoni”. Potreba za protekcionizmom poslednjih godina je na najstarijem kontinentu najčešće dovođena u vezu sa zaštitom od islamizacije Evrope. ${ }^{37}$

\section{Umesto zaključka: kuda plovi ovaj brod?}

Savremeni islamizam je istovremeno poziv na povratak izvornim vrednostima i praksama islama, pobuna protiv prevlađujućih socioekonomskih i političkih odnosa u muslimanskom svetu, ali i zahtev za ukidanjem postojećeg sistema nejednake raspodele moći u međunarodnim odnosima. Kao što je već rečeno, karakter islamske politike razlikuje se u zavisnosti od toga ko ima tu moć da formuliše šta je „pravi” islam i koja je njegova uloga u državi i društvu. Drugim rečima, radi se ili o režimskom islamu vladajućih elita i s njima povezane službene uleme, ili o opozicionom islamu islamističkih grupa koje svoj aktivizam temelje na uverenju da je islam i religija i država. Kompleksan je odnos između islamizma i njegovog naizgled najžešćeg suparnika, a suštinski skoro pa ekvivalenta u vidu narastajućeg desnog ekstremizma u zemljama zapadnog sveta.

Krajnja evropska desnica, koristeći sve ukorenjeniju islamofobiju, jača u sve većem broju zapadnoevropskih nacija i sve uspešnije nameće svoj hegemoni ideološki projekat zasnovan na svojim bazičnim vrednostima nacionalizma, ksenofobije i autoritarnosti, često koketirajući sa tzv. hrišćanskim narativima, kao objedinjujućim, u otporu prema ovako proklamovanim opasnostima. Ekstremno desne stranke današnje Evrope su, bez izuzetka, naglašeno islamofobične i antiuseljenički usmerene $u$ praktičnoj politici. Na taj način one uspevaju da objedine otpor prema etničkoj (verskoj, kulturnoj) i fizičkoj ugroženosti. Prvi narativ protežira $a$ priori nepripadanje muslimana evropskoj civilizaciji, a drugi ističe kako useljenici ugrožavaju život i imovinu usled sklonosti kriminalu i islamističkom terorizmu. Useljenici se predstavljaju kao mladi avanturisti skloni kriminalu i ugrožavanju bezbednosti, imovine i života Evropljana,

${ }^{37}$ Više o (ne)opravdanosti straha od islamizacije Evrope u: Milovan Subotić, „(Ne)opravdan strah od islamizacije Evrope”, Viteška kultura - Chivarlous culture, br. 7, Beograd, 2018. str. 283-304. 
dok se jednovremeno čitav islam predstavlja kao neprijatelj Evrope i njenih hrišćanskih vrednosti. Istovremeno, deo evropske radikalne desnice koja korene vuče od neoliberala, insistira na priči baziranoj na tome da muslimani temeljno ugrožavaju ljudska prava i slobode ugroženih grupa jer ne razumeju, i ne žele da razumeju, da je žena odavno osvojila prava u zapadnim društvima, te da i homoseksualci imaju svoja zajamčena prava. Tako se iz ovog pravca ultradesnog delovanja podgreva moralna panika zbog ugroženosti „,naših" žena i zapadnih vrednosti, a licemerno se insistira na pravima muslimanki i LGBT populacije. ${ }^{38}$

Činjenica je da muslimanske manjine i ranije nisu bile najbolje uklopljene u evropska društva, te da su i do sada neretko bile suočene sa različitim diskriminatorskim praksama. Uporedo sa radikalizacijom prilika ovaj položaj je dalje regresirao i doveo do artikulacije nagomilanih frustracija $u$ kojima islamisti vide svoju priliku kroz transmisioni potencijal obespravljenih. Akti uličnog nasilja sa pretežno mlađim muslimanskim protagonistima širom evropskih gradova, a naročito teroristička delovanja koja su svoju kulminaciju na evropskom tlu doživela polovinom druge dekade ovog veka, svedoče o navedenom. Ulični nemiri koji često imaju i elemente otvorenog nasilja, naročito terorizam, širom otvaraju vrata rastu evropskih krajnje desnih ideja i njihovih ovaploćenja, što bi u nekom najgorem scenariju moglo da dovede do fašizacije radikalnih desničara sa potencijalom masovnih progona manjinskog muslimanskog stanovništva. Tako bi, kao što to s pravom primećuje Bakić, „Hantingtonovo proročanstvo o sukobu civilizacija bilo konačno potvrđeno, ali to se ne bi dogodilo kao posledica na nauci zasnovanog predviđanja", već na pogrešnom odgovoru na islamizam. ${ }^{39}$ Dok bi zemlje savremenog Zapada trebale preispitati politiku prema osobenostima percipiranja demokratije u muslimanskim zemljama, što bi za posledicu imalo i relaksiranje recidiva loše politike usmerene prvenstveno prema evropskom kontinentu, muslimanski živalj $\mathrm{u}$ domicilnim zemljama i u rasejanju bi se morao značajnije pozabaviti pretnjom koju za sam islam predstavljaju islamistički ekstremisti.

I na kraju, ko ima koristi od ovakvog razvoja događaja? Ovaj odgovor nije naročito komplikovan. Korist imaju i islamisti i ekstremni evropski desničari koji mašu hrišćanskim ornamentima. Danas, u vremenu političkih

\footnotetext{
${ }^{38}$ Prema: Jovo Bakić, Evropska krajnja desnica: 1945-2018, Clio: Beograd, str. 111. ${ }^{39}$ Ibid.
} 
interpretacija ovih religija, uočljivo je da oni koji vešto manipulišu određenim doktrinama ovih verskih učenja funkcionišu prema principu spojenih sudova. Politički islam (islamska desnica) tako osnažuje političko hrišćanstvo (hrišćanska desnica), a događaji posle 11. septembra 2001. godine, i naročito naglašen antiislamski odgovor značajnog dela političkih aktera današnje Evrope na recidive "Arapskog proleća”, u vidu brojnih terorističkih akcija na evropskom tlu i migrantskog talasa prema najstarijem kontinentu, to najbolje potvrđuju. Desničari zasad trljaju ruke, islamisti takođe.

\section{Bibliografija}

Al-Ghannouchi, Rashid, "Secularism in the Arab Maghreb", in: John Esposito, Azzam Tamimi, (eds.), Islam and Secularism in the Middle East, Hurst \& Company, London, 2002.

Andrić, Zoran, „Ima li Evropa odgovor na islamizam?”, Danas, 3. jun 2016. Bakić, Jovo, Evropska krajnja desnica: 1945-2018, Clio, Beograd, 2019.

Blokland, Theodorus Hans, Freedom and culture in western society, Routledge, London, 1997.

Brubaker, Roger, "Economic crisis, nationalism, and politicized ethnicity", in: Calhoun Craig, and Derluguian Georgi (eds.), The Deepening Crisis: Governance Challenges after Neoliberalism, Social Science Research Council and NYU Press, New York, 2011. pp. 93-108.

Cevik, Salim, "Myths and Realities on Islam and Democracy in the Middle East", Estudios Políticos, No. 38, 2011, pp. 121-144.

Despotović, Ljubiša, Globalizacija i geopolitika identiteta, Kairos, Sremski Karlovci, 2017.

Dessouki, Hillal and Korany, Bahgat, Globalization and Arab Foreign Policies: Constraints or Marginalization?, The American University in Cairo Press, Cairo-New York, 2010.

Dessouki, Hillal, Islamic Resurgence in the Arab World, Praeger Publishers, New York, 1982.

Fuller, Graham, The Future of Political Islam, Palgrave MacMillan, New York, 2003.

Goerres, Achim, Spies C. Dennis, Kumlin, Staffan, The Electoral Supporter Base of the Alternative for Germany, Social Science Research Network, Rochester, NY, 2017. 
Jovanović, Nataša, Ajzenhamer, Vladimir, „Unifikacija islama kao instrument hantingtonizacije migrantske krize", u: Valić Nedeljković Dubravka, Gruhonjić Dinko (ur.), Populizam, izbeglička kriza, religija, mediji, medijska istraživanja, Filozofski fakultet, Novi Sad, 2017, str. 255-268.

Korany, Bahgat and Dessouki, Hilal, The Foreign Policies of Arab states: The Challenge of Change, London, Routledge, 2019.

Kulenović, Tarik, Politički islam: osnovni pojmovi, autori i skupine jednog modernog političkog pokreta, VBZ, Zagreb, 2008.

Mehanović, Muhamed Nezir, „Osnovne islamske dužnosti i njihov utjecaj na izgradnju morala", Preporod, Sarajevo, 4. jun 2017.

Moffitt, Benjamin, The Global Rise of Populism: Performance, Political Style, and Representation, Stanford University Press, Redwood City, 2016.

Offe, Claus, Europe entrapped, Polity, Cambridge, Malden MA, 2016.

Roy, Olivier, The Failure of Political Islam, Harvard University Press, Cambridge, Massachusetts, 1994.

Ruthven, Malise, Fundamentalism: The Search for Meaning, Oxford University Press, Oxford, 2004.

Rydgren, Jens, and Van der Meiden, Sara, "Sweden, Now a Country Like All the Others? The Radical Right and the End of Swedish Exceptionalism", Working Paper, Department of Sociology, Stockholm University, 2016.

Seidensticker, Tilman, "Islamismus. Geschichte, Vordenker, Organisationen", C.H. Beck Verlag, Munchen, 2014.

Shook, John, "Paul Kurtz, Atheology, and Secular Humanism", Essays in the Philosophy of Humanism, Vol. 21, No. 2, 2013, pp. 111-116.

Subotić, Milovan, "(Ne)opravdan strah od islamizacije Evrope”, Viteška kultura - Chivarlous culture, br. 7, Beograd, 2018, str. 283-304.

Subotić, Milovan, Dimitrijević, Ivan, „Populizam kao generator desnog ekstremizma na primeru migrantske krize“ , Kultura polisa, Br. 38. 2019, str. 295-310.

Vogelsang-Eastwood, Gillian, "Reza Shah's Dress Reforms in Iran", in: Vogelsang-Eastwood Gillian (ed.), Berg Encyclopedia of World Dress and Fashion, Central and Southwest Asia, Berg Publishers, Oxford, 2010, pp. 308-312. 
Vossen, Koen, The Power of Populism: Geert Wilders and the Party for Freedom in the Netherlands, Taylor \& Francis, Milton Park, 2016.

Wiktorowicz, Quintan and Kaltenthaler Karl, “The rationality of radical Islam", Political Science Quarterly, Vol. 121, No. 2, 2006, pp. 295-319.

Wiktorowicz, Quintan, "Introduction: Islamic Activism and Social Movement Theory", in: Wiktorowicz Quintan (ed.), Islamic Activism: A Social Movement Theory Approach, Indiana University Press, Bloomington, 2004, pp. 1-32.

Zirojević, Olga, „Šiiti i suniti”, Republika, 592-599, 30. jun 2015.

Zubaida, Sami, Islam, the People and the State: Political Ideas and Movements in the Middle East, I. B. Taurus \& Co, London and New York, 2009.

\section{Izvori sa interneta}

Bojić, Saša, „Nemačka štampa: Pobednici izbora kao pokisle pudle”, Deutsche Welle na srpskom jeziku, 2. septembar 2019. https:/ / www.dw. com/sr/pobednici-izbora-kao-pokisle-pudle/a-50257334 25/5/2020

Hamid, Shadi and Dar, Rashid, "Islamism, Salafism, and jihadism: A primer", Markaz, July 15, 2016, https://www.brookings.edu/blog/ markaz/2016/07/15/islamism-salafism-and-jihadism-a-primer / 29/05/2020.

Hardeep, Matharu, "Slovakian Prime Minister says 'Islam has no place in this country' - weeks before it takes over EU presidency", Independent, May 27, 2016,

https://www.independent.co.uk/news/world/europe/islam-has-noplace-in-this-countrysays-slovakian-prime-minister-weeks-before-ittakes-over-eu-a7052506.html, 12/01/2020.

Novak, Benjamin, “Orbán: Hungary's sovereignty depends on receiving EU funds", The Budapest Beacon, September 18, 2015, https:/ / budapest beacon.com/ orbanhungarys-sovereignty-depends-on-receiving-eufunds/, 11/14/2020.

"Number of Refugees to Europe Surges to Record 1.3 Million in 2015", Pew Research Center - Global Attitudes \& Trends, August 1, 2016. http: / / www.pewglobal.org/ 2016/08/02/number-ofrefugees-toeurope-surges-to-record-1-3-million-in-2015/pgm_2016-08-02_europeasylum11/03/2020. 


\section{„Švedsko upozorenje Evropi", Radio Slobodna Evropa, 11. septembar 2018. https://www.slobodnaevropa.org/a/\%C5\%A1vedska-izbori-rezultati- desnica-poruke-evropa-populizam- /29481858.html 14/01/2020.}

\section{Milovan SUBOTIĆ}

\section{ISLAMISM AND EUROPEAN RIGHT RESPONSE: PUTTING OUT FIRE WITH GASOLINE}

Abstract: The scope of modern Islamism is complex. It is simultaneously the call for a return to the original values and practices of Islam and a rebellion against the predominant social-economic and political relations in the Muslim world. Also, Islamists articulate a request for the abolition of the existing system of unequal power distribution in international relations. The character of Islamic politics differs in relation to who has the power to formulate the "real" Islam and what is its role in a nation and society. On the one hand, we talk about the so-called regime of Islam ruling elites and related official ulama (Muslim scholars). On the other hand, we are talking about the opposition of Islamist groups that have their activism based upon the belief that Islam is both religion and a nation. The relationship between Islamism and its seemingly worst opponent is essentially almost equivalent to the form of the rising right extremism in the West countries. Extremist right parties of contemporary Europe are, without exception, mostly Islamophobic and focused against migration in practical policy. Migrants are depicted as young, adventurous, prone to crime and endangering the safety, property, and life of Europeans. At the same time, Islam as a whole is presented as the adversary of Europe and its Christian values. The part of European radical right that has its roots in neoliberalism insists on the idea that the Muslims are basically threatening human rights and freedoms of endangered groups. The fact is that Muslim minorities were ill-fit into European societies before and that they were often faced with different discriminatory practices. Parallel with the radicalization of opportunities, this situation further regressed and led to the frustration of the deprived. At that moment, the Islamists arrived through the transmission potential of the deprived. Acts of street violence with mostly younger Muslim protagonists across European cities and especially terrorist attacks on European soil testify about the afore-mentioned. This development suits the European far-right, and the chain of violence continues. According to the worst scenario, the situation could be further radicalized. Islamists could radicalize their actions, and radical right could enter the phase of fascism with the potential of mass persecution of the minority Muslim population. Thus, Huntington's "prophecy" about the clash of civilizations could finally be validated. However, it would not happen as a consequence of science-based foreknowledge, but on erroneous response to Islamism. Finally, who will benefit from this 
development of events? The answer is not particularly complicated. Both Islamists and extreme European rightists waving with Christian ornaments benefit from that. Today, in times of political interpretations of these religions, it is noticeable that those who masterly manipulate with certain doctrines of these religious teachings function like a system of communicating vessels. Political Islam (Islamic right), in such a way, empowers political Christianity (Christian right). The events after September 11, 2001, and emphasized antiIslamic response of a significant number of today's Europe political actors to the relapses of the "Arab Spring" are the best verification of that. Meanwhile, both right-wingers and Islamists are rubbing their hands.

Keywords: Islamism, far-right, conflict, terrorism, populism, democracy. 